\title{
Analisa Video Share To Video Likes Ratio Tiktok Pada 5 Merek Hp Terbaik Di Dunia Tahun 2021
}

\author{
I Wayan Siriya \\ wayansiriya02@gmail.com
}

\begin{abstract}
ABSTRAK
Tik Tok is an application where users can share music videos of short duration. TikTok was introduced and first launched in September 2016. At that time, the application was immediately accepted in Indonesia. But indeed, at that time many called TikTok users as alayers. In the world of Tiktok users reaching 732 million in October 2020 active users, The large number of active users on Tiktok can provide an opportunity for brands to make the TikTok platform a social media marketing platform. The 5 Best Mobile Brands in the World in 2021 that use TikTok as a marketing platform, namely: Samsung, Iphone, Xiaomi, Oppo, Huawei. The purpose of this study is to calculate the credibility of the TikTok account performance of the 5 Best Mobile Brands in the World in 2021. The method used for this research is a quantitative exploratory method. The results of this study indicate that the Oppo hp brand is ranked first and has good account performance credibility.
\end{abstract}

\begin{abstract}
ABSTRAK
Tik Tok merupakan sebuah aplikasi di mana para penggunanya bisa berbagi video musik dengan durasi pendek. TikTok dikenalkan dan diluncurkan pertama kali pada September 2016. Pada saat itu, aplikasi ini langsung diterima di Indonesia. Namun memang, saat itu banyak yang menyebut pengguna TikTok sebagai seorang alayers. Di dunia pengguna Tiktok mencapai 732 juta pada Oktober 2020 pengguna yang aktif, Maraknya jumlah pengguna yang aktif di Tiktok dapat memberikan peluang bagi brand untuk menjadikan platform TikTok sebagai platform social media marketing. Adapun 5 Merek Hp Terbaik Di Dunia Tahun 2021 yang memanfaatkan TikTok sebagai platform marketing, yaitu : Samsung, Iphone, Xiaomi, Oppo, Huawei. Tujuan dari penelitian ini yaitu untuk menghitung kredibilitas dari performa akun TikTok 5 Merek Hp
\end{abstract}


Terbaik Di Dunia Tahun 2021. Metode yang digunakan untuk penelitian ini yaitu metode eksploratif kuantitatif. Hasil dari penelitian ini menunjukan bahwa merek hp Oppo mendapatkan peringkat pertama dan memiliki kredibilitas performa akun yang baik

Keyword : Credibility Account TikTok ; Social Media Marketing ; Social Media TikTok ;

Video Share to Video Likes Ratio ; Merek Hp Terbaik di Dunia Tahun 2021

\section{PENDAhUluAN}

Di jaman yang semakin canggihnya teknologi informasi dan komunikasi yang berkembang saat ini, segala sesuatu dapat diselesaikan dengan cara-cara yang praktis. Kehidupan manusia yang bermula dari kesederhanaan kini menjadi kehidupan yang bisa dikategorikan sangat modern, teknologi informasi dan komunikasi merupakan sesuatu yang bermanfaat untuk mempermudah semua aspek kehidupan manusia. Dunia informasi saat ini seakan tidak bisa terlepas dari teknologi. Penggunaan teknologi informasi dan komunikasi oleh masyarakat menjadikan dunia teknologi semakin lama semakin canggih.

Dengan kemajuan teknologi yang begitu pesat, hal ini disebabkan karena semakin cepatnya akses informasi dalam kehidupan sehari-hari. Teknologi internet sudah menjadi kebutuhan bagi masyarakat hal inilah yang melahirkan sosial media, sosial media menjadi budaya populer dengan beragam keunikannya serta fenomena kehadirannya yang tidak bisa diduga sebelumnya (Irwanto, 2017). Saat ini sudah banyak media sosial yang digunakan sebagai alat komunikasi, salah satu contoh media sosial dengan pengguna paling banyak yaitu TikTok. Tik Tok merupakan aplikasi Sosial Media yang menjadi budaya populer di Indonesia mulai awal tahun 2020 ini. Tik Tok sendiri dalam pelafalan bahasa cina di sebut Douyin yang merupakan aplikasi video musik yang pada awalnya digunakan untuk hiburan lipsync lagu oleh penggunanya. (Hasiholan, Pratami, and Wahid 2020).

Aplikasi sosial berbasis video ini mendapat banyak perhatian dari masyarakat terutama pada generasi muda, penggunaan media sosial TikTok telah menjadi sebuah rutinitas remaja khususnya mahasiswa pada saat ini (M. $\Theta E O \Delta \Omega P O Y$, Paz, and Ruíz 2020). Pada awal Agustus tahun lalu, Tik Tok memiliki 600 juta pengguna diseluruh dunia. Aplikasi ini telah membantu 
banyak bisnis menjangkau target pelanggan dan pasar di masa depan. Melihat dari sudut pandang seorang pemasar dalam mencari target pasar, orang akan lebih suka mempromosikan pada saluran yang berbeda untuk menarik pelanggan. Banyak akun brand-brand terkenal yang ada pada Tiktok seperti merek hp terbaik di dunia, adapun 5 Merek Hp Terbaik Di Dunia Tahun 2021 seperti Samsung, Iphone, Xiaomi, Oppo, Huawei (Setiadid 2021).

Penelitian ini menggunakan metode eksploratif kuantitatif, dan akan menghitung menggunakan rasio-rasio yang ada pada TikTok. Pada penelitian menjelaskan bahwa terdapat 17 rasio yang ada pada sosial media TikTok dan relevan digunakan sebagai media ukur kredibilitas akun yang ada. Penelitian ini hanya berfokus untuk menghitung kredibilitas Video Share to Video Likess Ratio pada 5 Merek Hp Terbaik Di Dunia Tahun 2021, diantaranya yaitu Samung, Iphone, Xiaomi, Oppo, Huawei (Setiadid 2021). Tujuan dari penelitian ini adalah mengetahui kredibilitas performa dari akun TikTok 5 Merek Hp Terbaik Di Duni Tahun 2021 menggunakan Video Share to Video Likess Ratio.

\section{TINJAUAN PUSATAKA}

Kemajuan Teknologi informasi dan Komunikasi telah membuka tahap baru bagi masyarakat untuk memperoleh informasi secara otonom. Banyak aplikasi - aplikasi serta platform media sosial yang bermunculan seperti Facebook, Whatsapp, Instagram, Tiktok, Twitter dan lain sebagainya. Dari berbagai kalangan dan usia hampir semua masyarakat Indonesia memiliki dan menggunakan media sosial sebagai salah satu sarana guna memperoleh dan menyampaikan informasi ke public. Tiktok menjadi aplikasi paling popular di dunia saat ini sejak diluncurkan ke publik oleh ByteDance pada 2018 (Ridhoi 2020). Tiktok menjadi aplikasi yang memiliki pengguna aktif terbanyak dari aplikasi sosial media lainnya.

Dalam penggunaannya aplikasi TikTok memiliki muatan positif, misalnya sebagai ajang hiburan, satu seni, mengimplementasikan dan mengeksistensi diri untuk memberikan kepuasan bagi dirinya sendiri maupun orang lain, selain itu dengan menggunakan aplikasi Tik Tok penggunannya dapat mengeluarkan kreativitas dan bakat yang dimiliki misalnya seperti bernyanyi, menari dan membuat konten-konten video seru yang unik sampai dapat menjadikan seorang sebagai influencer seperti artis, selebgram, youtuber dan lainnya. 
Tiktok berhasil mengambil ketertarikan dari berbagai kalangan sehingga mempunyai rasa keingin tahuan dalam pembuatan video pendek di Tiktok. TikTok juga memberikan contoh gerakan video yang akan ditiru, dalam setiap gerakan dan music Tiktok memberikan effect yang lucu sehingga pengguna tertarik dalam penggunaan Tiktok yang di berikan contoh oleh pihak Tiktok sehingga para pengguna dapat meniru gerakannya.(Hasiholan, Pratami, and Wahid 2020).

Aplikasi media sosial Tiktok ini tidak hanya digunakan untuk membuat konten video tetapi juga menimbulkan peluang bagi masyarakat dalam melakukan suatu usaha. Banyak platform media social yang dapat digunakan untuk digital marketing atau memasarakan suatu produk yang dapat dikemas secara menarik ke khalayak umum untuk mempertahankan bisnisnya salah satu nya pada aplikasi Tiktok. Tiktok menjadi salah satu platform yang sedang sangat digemari saat ini, banyak perusahaan atau brand yang menggunakan Tiktok sebagai platform social media marketing. Strategi marketing yang dapat dilakukan dengan platform Tiktok salah satunya dengan menggunakan hashtag (\#) atau melakukan kolaborasi dengan para influencer yang sedang digemari dan memiliki banyak pengikut sehingga strategi promosi yang dilakukan lewat Tik Tok dapat memikat dan menarik banyak orang. (Electric 2021). Sehingga menimbulkan kualitas akun yang menentukan kredibilitas pemilik akun. Kredibilitas dapat di ukur dari tingkat performa sebuah akun, diperlukan skala pengukuran yang tertuang ke dalam ratio.

\section{METODE PENELITIAN}

Penelitian ini menggunakan metode eksploratif kuantitatif untuk mengetahui kredibilitas dari performa akun TikTok 5 Merek Hp Terbaik di Dunia Tahun 2021. Metode eksploratif merupakan metode penelitian yang bertujuan memperdalam pengetahuan dan mencari ide-ide baru mengenai suatu gejala tertentu, menggambarkan fenomena sosial, dan menjelaskan bagaimana terjadinya suatu fenomena sosial untuk merumuskan masalah secara lebih terperinci atau mengembangkan hipotesis bukan menguji hipotesis.(Mudjiyanto 2018).

Tujuan dari penelitian ini yaitu mengetahui nilai kredibillitas dari performa akun TikTok 5 Merek Hp Terbaik di Dunia Tahun 2021. Ada beberapa langkah yang harus dilakukan dalam penelitian ini, sehingga mampu menemukan peringkat pertama akun TikTok Merek hp terbaik di 
dunia tahun 2021 yang memiliki performa terbaik. Langkah-langkah yang dilakukan pada penelitian ini, diantaranya yaitu

\section{Melakukan Eksplorasi Pada Website Untuk Menentukan Objek yang Akan Dianalisa.}

Eksplorasi dilakukan pada beberapa halaman website yang menyediakan informasi mengenai objek yang di teliti. Setelah ekslorasi selesai dilakukan, maka ditemukan namanama merk hp terbaik di dunia yang akan di jadikan objek analisa. Setelah melakukan eksplorasi pada halaman website, maka langkah selanjutnya mencari nama akun TikTok dari masing-masing merek hp. Di pastikan semua merek hp memiliki akun pada aplikasi sosial media TikTok.

\section{Menghitung Nilai Rata-Rata Variable Dari 5 Merek Hp Terbaik Di Dunia Tahun} 2021.

Pada bagian ini, peneliti menghitung nilai variable video share dan variable video likes. Variabel merupakan besaran yang dapat berubah serta berpengaruh pada sebuah peristiwa atau hasil dari penelitian. Keberadaan variabel sendiri nantinya bisa mempermudah Anda untuk menganalisis atau mengidentifikasi permasalahan yang ada. Untuk menghitung nilai rata-rata dari variabel video share dan variabel video likes yaitu dengan cara mengambil minimal 10 postingan kemudian di hitung sehingga menemukan nilai ratarata dari masing-masing variabel.

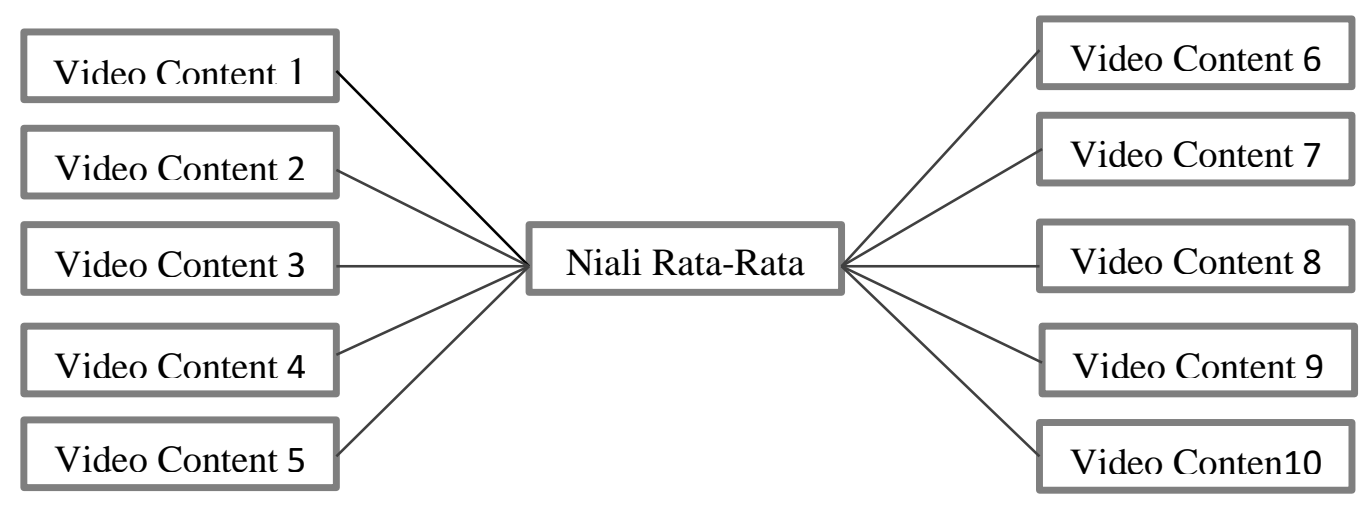

Gambar 1 Analisis Nilai Rata-Rata Variabel 


\section{Menghitung Nilai Kredibilitas Rasio}

Untuk menghitung nilai kredibilitas dari video Share to video likes ratio, peneliti menggunakan cara membgai nilai variabel pertama dengan nilai variabel kedua. Jika video share memiliki nilai 200 dan video views memiliki nilai 300, maka cara menghitungnya yaitu $200: 300=0,6$. Dengan begitu nilai dari video share to video likes ratio adalah 0,6 .

\section{Menentukan Peringkat Pada Akun TikTok}

Pada langkah terakhir yang dilakukan pada penelitian ini yaitu menentukan peringkat pada masing-masing rasio yang ada. Pada penentuan peringkat perlu melihat karakteristik dari rasio yang di teliti. Jika karakteristik rasio merupakan rendah, maka objek yang memiliki nilai terendah akan mendapatkan angka 5 dan objek yang memiliki nilai tertinggi akan mendapatkan angka 1. Jika rasio memiliki karakteritik tinggi maka objek yang mendapatkan nilai tinggi akan mendapatkan angka 5 dan objek yang mendapatkan nilai terendah akan mendapatkan angka 1. Setelah mendapatkan hasil kredibilitas ratio maka bisa disimpulkan bahwa objek yang mana mendapatkan peringkat 1 sampai peringkat 5 .

\section{HASIL DAN PEMBAHASAN}

Akun Tiktok dari 5 Merk Hp Terbaik Di Dunia Tahun 2021, yaitu:

\section{Samsung}

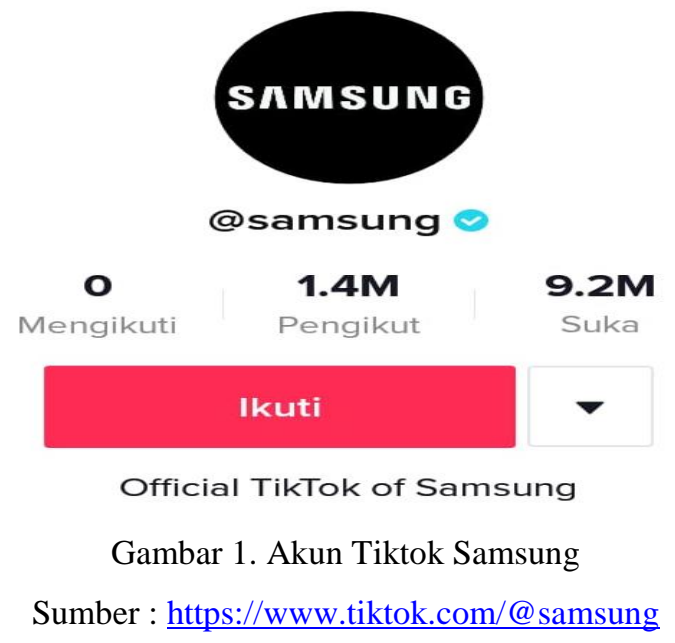




\section{Iphone}

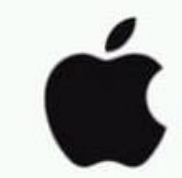

@apple ○

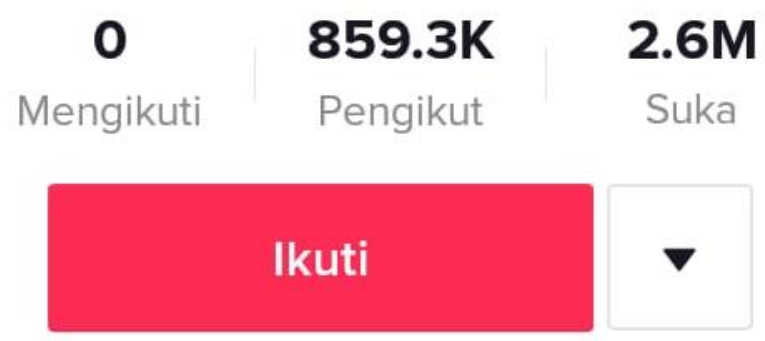

Gambar 2. Akun Tiktok Aplle

Sumber : https://www.tiktok.com/@apple

\section{Xiaomi}

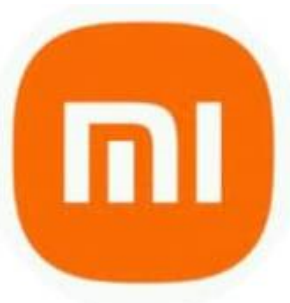

\section{@xiaomi.official}

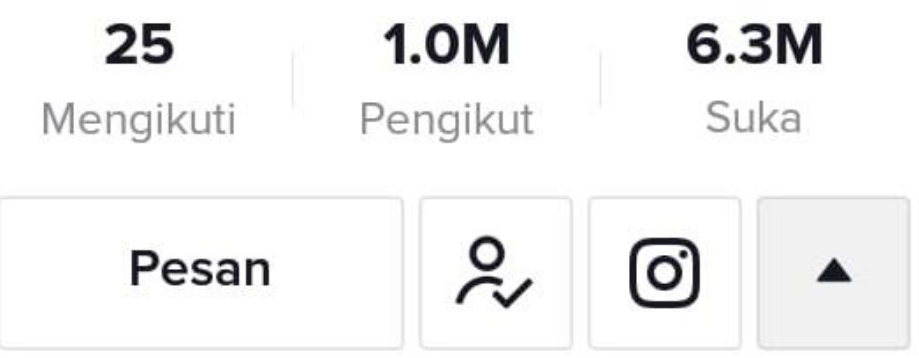

Gambar 3. Akun Tiktok Xiaomi

Sumber : https://www.tiktok.com/@xiaomi.official 


\section{Oppo Indonesia}

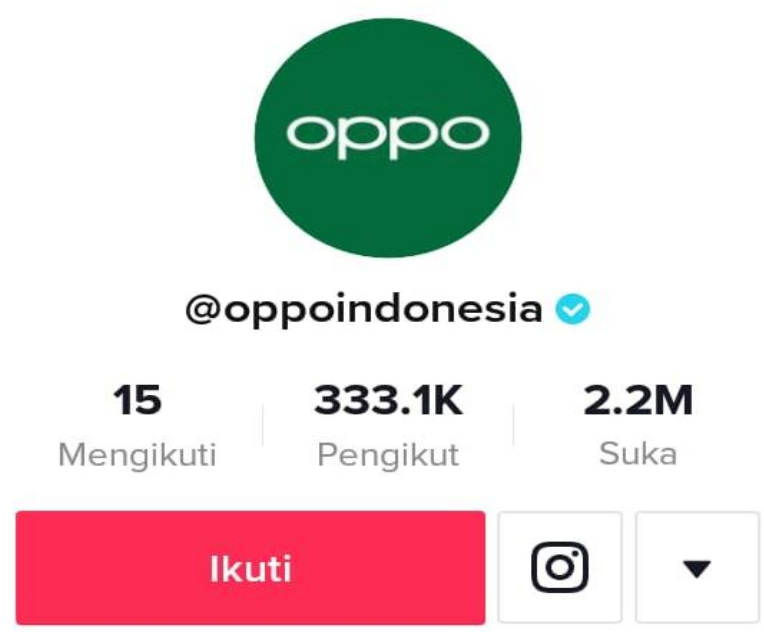

Nikmati keindahan teknologi dari OPPO.

$\mathcal{S}$ www.oppo.com/id/

Gambar 4. Akun Tiktok Oppo Indonesia

Sumber : https://www.tiktok.com/@oppoindonesia

\section{Huawei}

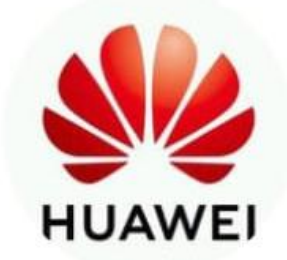

@huaweiukofficial

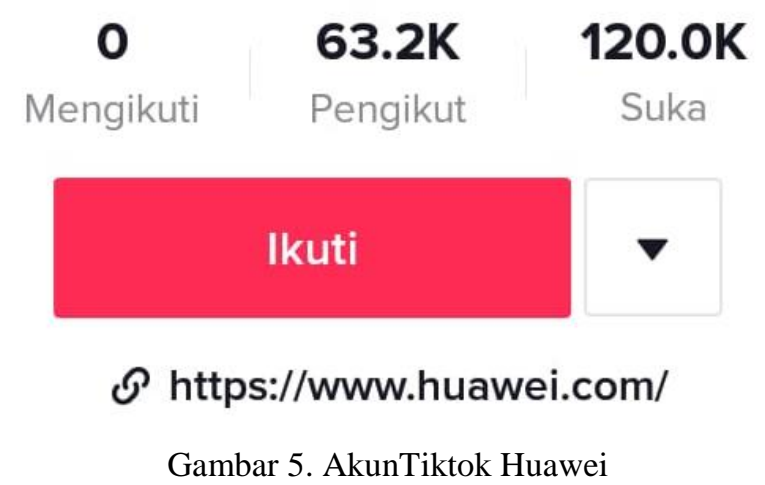

Sumber : https://www.tiktok.com/@huaweiukofficial 
Dari kelima akun Tiktok 5 Merk Hp Terbaik Di Dunia Tahun 2021, peneliti menemukan nilai dari masing-masing variable yang ada untuk menghitung rasio Video Share to Video Likes dari setiap akun. Pada akun Tiktok terdapat 7 variabel, diantaranya yaitu :

\author{
1. Likes
}

2. Followers

3. Following

4. Video Likes

5. Video Comments

6. Video Share

7. Video Views

Dari ketujuh Variabel tersebut peneliti hanya fokus untuk menemukan hasil dari 2 variabel, yaitu:

1. Video Share

2. Video Likes

Dari kedua variabel tersebut kemudian dianalisa sehingga menemukan nilai rata-rata dari variabel video share dan variabel video likes. Untuk menghitung nilai rata-rata dari variabel video share dan variabel video likes yaitu dengan cara mengambil minimal 10 postingan kemudian di hitung sehingga menemukan nilai rata-rata dari masing-masing variabel. Berikut merupakan tabel nilai rata-rata dari masing-masing 5 merk hp di dunia tahun 2021, yaitu : 
Tabel 1. Analisa Nilai Rata-Rata Variabel Video Share to Video Likes Akun Tiktok Samsung

\begin{tabular}{|r|r|r|}
\hline \multicolumn{1}{|c|}{ No } & \multicolumn{1}{|c|}{ Video share } & \multicolumn{1}{c|}{ Video likes } \\
\hline 1 & 13 & 1713 \\
\hline 2 & 84 & 3648 \\
\hline 3 & 92 & 6372 \\
\hline 4 & 31 & 2131 \\
\hline 5 & 16 & 1209 \\
\hline 6 & 61 & 3160 \\
\hline 7 & 9 & 1265 \\
\hline 8 & 26 & 1224 \\
\hline 9 & 88 & 3770 \\
\hline 10 & 88 & 4687 \\
\hline Total & $\mathbf{5 0 , 8}$ & $\mathbf{2 9 1 7 , 9}$ \\
\hline
\end{tabular}

Sumber : Pengolah Data Excel

Tabel 2. Analisa Nilai Rata-Rata Variabel Video Share to Video Likes Akun Tiktok Iphone

\begin{tabular}{|c|c|c|}
\hline No & Video share & Video likes \\
\hline 1 & 3089 & 377.200 \\
\hline 2 & 1294 & 293.400 \\
\hline 3 & 4662 & 520.500 \\
\hline 4 & 1210 & 417.300 \\
\hline Total & 2563,75 & 402.100 \\
\hline
\end{tabular}


Tabel 3. Analisa Nilai Rata-Rata Variabel Video Share to Video Likes Akun Tiktok Xiaomi

\begin{tabular}{|r|r|r|}
\hline \multicolumn{1}{l|l|}{ No } & \multicolumn{1}{|l|}{ Video share } & Video likes \\
\hline 1 & 333 & 52.800 \\
\hline 2 & 2248 & 118.900 \\
\hline 3 & 862 & 79.500 \\
\hline 4 & 7 & 1.559 \\
\hline 5 & 10 & 11.100 \\
\hline 6 & 50 & 4.849 \\
\hline 7 & 12 & 8.116 \\
\hline 8 & 2 & 875 \\
\hline 9 & 2 & 775 \\
\hline 10 & 1 & 819 \\
\hline Total & $\mathbf{3 5 2 , 7}$ & $\mathbf{2 7 . 9 2 9}$ \\
\hline
\end{tabular}

Sumber : Pengolah Data Excel

Tabel 4. Analisa Nilai Rata-Rata Variabel Video Share to Video Likes Akun Tiktok Oppo Indonesia

\begin{tabular}{|c|c|c|}
\hline No & Video share & Video likes \\
\hline 1 & 124 & 140 \\
\hline 2 & 394 & 23.200 \\
\hline 3 & 149 & 632 \\
\hline 4 & 170 & 936 \\
\hline 5 & 133 & 186 \\
\hline 6 & 102 & 590 \\
\hline 7 & 103 & 333 \\
\hline 8 & 165 & 471 \\
\hline 9 & 137 & 192 \\
\hline 10 & 164 & 507 \\
\hline Total & 164,1 & 2718,7 \\
\hline
\end{tabular}


Tabel 5. Analisa Nilai Rata-Rata Variabel Video Share to Video Likes Akun Tiktok Huawei

\begin{tabular}{|r|r|r|}
\hline \multicolumn{1}{|l|}{ No } & Video share & \multicolumn{2}{|l|}{ Video likes } \\
\hline 1 & 76 & 25.200 \\
\hline 2 & 65 & 38.600 \\
\hline 3 & 5 & 285 \\
\hline 4 & 1 & 162 \\
\hline 5 & 9 & 287 \\
\hline 6 & 8 & 410 \\
\hline 7 & 8 & 417 \\
\hline 8 & 18 & 481 \\
\hline 9 & 1 & 261 \\
\hline 10 & 2 & 163 \\
\hline Total & $\mathbf{1 9 , 3}$ & $\mathbf{6 . 6 2 7}$ \\
\hline
\end{tabular}

Setelah menghitung nilai rata-rata tersebut, maka akan menemukan hasil akhir nilai rata-rata dari variable Video Share dan Video Likes

Tabel 6. Nilai Variabel Pada Akun TikTok 5 Merek Hp Terbaik Di Dunia Tahun 2021

\begin{tabular}{|l|r|r|r|r|r|}
\hline \multicolumn{1}{|c|}{ Variable } & \multicolumn{1}{c|}{ Samsung } & \multicolumn{1}{c|}{ Iphone } & Xiaomi & Oppo Indoneia & \multicolumn{1}{c|}{ Huawei } \\
\hline Video share & 50,8 & 2563,75 & 352,7 & 164,1 & 19,3 \\
\hline Video likes & 2917,9 & 402.100 & 27.929 & 2718,8 & 6.627 \\
\hline
\end{tabular}

Pada akun TikTok terdapat 17 rasio yang relevan digunakan untuk mengukur kredibilitas pada masing-masing akun. Namun pada penelitian kali ini hanya berfokus untuk menghitung Video Share to Video Likes Ratio. Untuk menghitung kredibilitas dari masing-masing akun TikTok setiap 5 merek hp terbaik, peneliti menghitung dengan cara : variabel 1 akan dibagi dengan variabel 2, sehingga ditemukan hasil analisisa dari rasio tersebut. 
Tabel 7. Hasil Perhitungan Rasio Akun Tiktok

\begin{tabular}{|c|c|c|c|c|c|c|}
\hline $\begin{array}{c}\text { N } \\
\text { o }\end{array}$ & Ratio & Samsung & Iphone & Xiaomi & $\begin{array}{c}\text { Oppo } \\
\text { Indonesia }\end{array}$ & Huawei \\
\hline & $\begin{array}{c}\text { Video } \\
\text { Share to }\end{array}$ & & & & & \\
\cline { 2 - 6 } 1 & & & & & \\
& Video & 0,017409781 & 0,006375902 & 0,012628451 & 0,060357511 & 0,00291232 \\
& Likes & & & & 8 \\
& Ratio & & & & & \\
\hline
\end{tabular}

Video Share to Video Likes Ratio memiliki karakteristik yang tinggi, artinya semakin tinggi nilai yang dihasilkan maka semakin baik kredibilitas dari performa akun tersebut. Untuk memberikan peringkat pada masing-masing 5 merk hp terbaik di dunia tahun 2021, peneliti memberikan angka 5 kepada merek hp yang mendapatkan nilai tertinggi dan angka 1 untuk 5 merk hp terbaik di duni tahun 2021 yang mendapatkan nilai terendah. Berikut merupakan tabel urutan nilai yang dihasilkan oleh masing-masing merk hp terbaik di dunia tahun 2021.

Tabel 8. Nilai Rasio Akun TikTok 5 Merk Hp Terbaik Di Dunia Tahun 2021

\begin{tabular}{|c|c|c|c|c|c|}
\hline Ratio & \multicolumn{5}{|c|}{ Nilai } \\
\hline \multirow{2}{*}{$\begin{array}{c}\text { Video Share } \\
\text { to Video } \\
\text { Likes }\end{array}$} & Samsung & Iphone & Xiaomi & $\begin{array}{c}\text { Oppo } \\
\text { Indonesia }\end{array}$ & Huawei \\
\cline { 2 - 6 } & 4 & 2 & 3 & 5 & 1 \\
\hline
\end{tabular}

Dari Tabel Nilai Rasio Akun TikTok 5 Merk Hp Terbaik Di Dunia Tahun 2021 dapat simpulkan bahwa Oppo Indonesia mendapatkan nilai tertinggi untuk rasio Video Share to Video Likes. Sedangkan akun TikTok Huawei mendapatkan nilai terendah untuk rasio ini. Jadi, pada penelitian ini Oppo Indonesia memiliki kredibilitas performa yang lebih baik dibandingkan dengan 5 merek hp lainnya.(Hasiholan, Pratami, and Wahid 2020) 


\section{KESIMPULAN}

Tujuan dari penelitian ini adalah mengetahui performa dari akun TikTok 5 Merk Hp Terbaik Di Dunia Tahun 2021 menggunakan Video Share to Video LIkes Ratio. 5 Merk Hp Terbaik Di Dunia Tahun 2021 yaitu : Samsung, Iphone, Xiaomi, Oppo Indonesia, Huawei. Dari kelima vendor smartphone tersebut dapat disimpulkan bahwa :

1. Peringkat pertama diraih oleh Oppo Indonesia dengan nilai tertinggi yaitu 0,060357511 .

2. Peringkat kedua diraih oleh Samsung dengan nilai 0,017409781.

3. Peringkat ketiga diraih oleh Xiaomi dengan nilai 0,012628451.

4. Peringkat keempat diraih oleh Iphone dengan nilai 0,006375902.

5. Peringkat kelima diraih oleh Huawei dengan nilai terendah yaitu 0,002912328 


\section{DAFTAR PUSTAKA}

Aprilian, Devri, Yessy Elita, and Vira Afriyati. 2020. "Hubungan Antara Penggunaan Aplikasi Tiktok Dengan Perilaku Narsisme Siswa Kelas VIII Di SMP Negeri 8 Kota Bengkulu.” Consilia : Jurnal Ilmiah Bimbingan Dan Konseling 2 (3): 220-28. https://doi.org/10.33369/consilia.2.3.220-228.

Bulele, Yohana Noni, and Tony Wibowo. 2020. "Analisis Fenomena Sosial Media Dan Kaum Milenial: Studi Kasus Tiktok." Conference on Business, Social Sciences and Innovation Technology 1 (1): 565-72. http://journal.uib.ac.id/index.php/cbssit.

Electric, Mitsubishi. 2021. "Pemanfaatan Media Sosial Tiktok." https://emea.mitsubishielectric.com/ar/products-solutions/factory-automation/index.html.

Hasiholan, Togi Prima, Rezki Pratami, and Umaimah Wahid. 2020. "Pemanfaatan Media Sosial Tik Tok Sebagai Media Kampanye Gerakan Cuci Tangan Di Indonesia Untuk Mencegah Covid-19." Communiverse : Jurnal Ilmu Komunikasi 5 (2): 70-80. https://doi.org/10.36341/cmv.v5i2.1278.

Marini, Riska. 2019. Pengaruh Media Sosial Tik Tok Terhadap Prestasi Belajar Peserta Didik Di SMPN 1 Gunung Sugih Lab. Lampung Tengah.

Mudjiyanto, Bambang. 2018. “Tipe Penelitian Eksploratif Komunikasi.” Jurnal Studi Komunikasi Dan Media 22 (1): 65. https://doi.org/10.31445/jskm.2018.220105.

Oktaheriyani, Desy, M Ali Wafa, and Shen Shadiqien. 2020. “Analisis Perilaku Komunikasi Pengguna Media Sosial TikTok (Studi Pada Mahasiswa Fakultas Ilmu Sosial Dan Ilmu Politik UNISKA MAB Banjarmasin ).” Jurnal Ilmu Sosial Dan Ilmu Politik, 7-52. http://eprints.uniska-bjm.ac.id/id/eprint/3504.

Ridhoi, Muhammad Ahsan. 2020. "Rahasia TikTok Meraih Popularitas Hingga Terancam Diblokir Trump." https://katadata.co.id/muhammadridhoi/digital/5f27d024839a3/rahasiatiktok-meraih-popularitas-hingga-terancam-diblokir-trump.

Setiadid. 2021. “5 Merk Hp Terbaik Di Dunia Tahun 2021.” Adiozh.Com. 2021. https://adiozh.com/2021/06/06/5-merk-hp-terbaik-di-dunia-tahun-2021/. 
Usrina, Nora. 2021. "Pengaruh Media Sosial Tiktok Terhadap Gaya Komunikasi Santri Taman Pendidikan Al-Qur'an Ar-Risalah." Journal of Chemical Information and Modeling 53 (9): 1689-99.

M. $\Theta E O \Delta \Omega P O Y$, M. MHTPO $\Sigma Y \Lambda H$, Guillermina Baena Paz, and Arróliga Araica; Blandón Ruíz. 2020. “No 主観的健康感を中心とした在宅高齢者における 健康関連指標に関 する共分散構造分析Title” 3 (2017): 54-67. http://repositorio.unan.edu.ni/2986/1/5624.pdf. 